\title{
Use of satellite data for radiative energy budget study of Indian summer monsoon
}

\author{
P N Mahajan, G R Chinthalu and S Rajamani \\ Indian Institute of Tropical Meteorology, Pune 411 008, India
}

In this paper satellite-derived radiative energy budget such as shortwave radiative heating, longwave radiative heating and net radiation balance have been studied for the post-onset phase of summer monsoon 1979. Since clouds play an important role in determining diabatic heating field as well as being a reflection of status of the monsoon itself, the day to day evolution of clouds from TIROS-N satellite has been made. Satellite-derived radiative heating rates from surface to $100 \mathrm{hPa}$ were computed for each $100 \mathrm{hPa}$ thickness layer. These heating rates were then compared with the observed latitudinal distribution of total radiative heating rates over the domain of the study.

From the results of our study it was found that the characteristic features such as net radiative heating rates of the order of $0.2^{\circ} \mathrm{C} /$ day at upper tropospheric layer $(100-200 \mathrm{hPa})$ and cooling throughout the lower tropospheric layers with relatively less cooling between $500-700 \mathrm{hPa}$ layer observed in a case of satellite-derived radiative energy budget agree well with the characteristic features of observational radiative energy budget over the domain of the study. Therefore, it is suggested that radiative energy budget derived from satellite observations can be used with great potential and confidence for the evolution of the complete life cycle of the monsoon over the Indian region for different years.

\section{Introduction}

The paucity of conventional meteorological observations particularly over the oceanic regions of the monsoon area has been considered as one of the major factors in the lack of understanding of the evolution of the earth and atmosphere radiative energy budget over the key monsoonal heat source-sink areas. Spaceborne measurements obtained from GOES and TIROS-N satellites over the Monex region during 1979 offered an opportunity to study the evolution of energy budget over these areas during different phases of the monsoon. The summer Monex experiment was conducted over the Indian subcontinent from May to August 1979. This time period coincided with the second Special Observation Period (SOP) of the First GARP Global Experiment (FGGE). A combination of summer Monex and FGGE observations provided an unprecedented data set for the study of southwest monsoon. The evolution of summer monsoon is, to a large extent, an atmospheric response to differential heating fields. Hence, the primary goal of summer Monex was to identify the areas of heat sources and sinks associated with southwest monsoon (Fein and Kuettner 1980). All the basic data were derived from the full resolution GOES-IO (Indian Ocean) VISSR (Visible Infrared Spin Scan Radiometer) imagery and TIROS-N Sounder observations. Appropriate algorithms developed based on satellite measurements were used to derive high resolution fields of the component of radiation parameters for pre-onset, onset and post-onset phases of summer monsoon 1979. The satellite-derived estimates were carefully evaluated against available conventional surface based and dropsonde measurements in order to ensure reliable definition of heating function at the earth's surface and within the atmosphere.

During summer Monex 1979 Eppley pyranometers and pyrgeometers were mounted onboard CV 990 jet aircraft to measure the solar (or shortwave) and terrestrial (or longwave) radiative fluxes respectively. The instrumentation is discussed in detail in Ackerman

Keywords. Radiative energy budget; post-onset; summer monsoon. 
et al (1980). In addition to radiation measurements the research aircraft CV 990 was equipped with a dropsonde (DWS) launching platform. Assignment of vertical distribution of moisture, temperature, carbondioxide and ozone above the aircraft altitude, along with dropsonde temperature, moisture profiles enabled a theoretical evaluation of atmospheric radiative flux profiles. These are well illustrated in Radiative Energy Budget Atlas of the 1979 Southwest Summer Monsoon by Ackerman and Cox (1986). This atlas presents estimates of two components of diabatic fields i.e., tropospheric and surface radiation energy budgets. The tropospheric radiative convergence profiles were derived in a manner analogous to the one employed by Cox and Griffith (1979). This methodology combines observations of the vertical and horizontal distributions of temperature, moisture, carbon-dioxide, ozone, clouds and soil derived aerosols with radiative transfer calculations to yield estimates of the radiative divergence in the atmosphere. The surface radiative fluxes were determined in a similar manner, and are thus consistent with the radiative heating profiles. The qualitative accuracy was achieved based on the following components: (i) radiation calculation algorithms, (ii) fields of state parameters used as input to calculation algorithms, (iii) cloud and aerosol radiative properties used in the calculations and cloud and aerosol distributions. Making use of all these available satellite data, radiation energy parameters were studied over the domain $30^{\circ} \mathrm{S}$ to $30^{\circ} \mathrm{N}$ and $40^{\circ} \mathrm{E}$ to $100^{\circ} \mathrm{E}$. for post-onset phase of summer monsoon. The phase 23rd June - 30th June, 1979 was selected based on the work of Krishnamurti and Ramanathan (1982). Since clouds play an important role in determining the diabatic heating fields (as well as being a reflection of the status of monsoon itself), the day to day evolution of clouds as revealed by TIROS-N Satellite was examined. Similarly, the composite evolution of radiation energy budget parameters for post-onset phase of monsoon (in association with synoptic systems) was generated over the Indian region and is described in this study.

\section{Data}

\subsection{Satellite-derived longwave radiative heating and longwave surface fluxes}

Radiation calculation algorithms based on the integrated broadband emissivity model of Cox and Griffith (1979) were used for the computation of longwave radiative heating profiles and longwave surface fluxes. This model consists of six spectral bands for gaseous components and one band specially for the treatment of clouds. The broad band model results were in very good agreement with the research aircraft flux observations over the Indian region.
Absolute differences were generally less than $3 \%$. Hence, longwave radiative heating fields and longwave surface fluxes presented in the atlas of Ackerman and Cox (1986) showed high potential for the study of radiation balance over the Indian region. However, some uncertainty in radiative transfer calculations may arise from the uncertain knowledge of cloud geometrical thickness and its base/top height, besides its microstructure.

\subsection{Satellite-derived shortwave radiative heating and shortwave surface fluxes}

The shortwave radiative heating profiles and shortwave surface fluxes were calculated using the broadband absorptivity model of Cox and Griffith (1979). This model has three bands for gaseous components i.e., for water vapour, carbon-dioxide and ozone. A comparison of shortwave radiative heating profiles (computed using broadband model) were in excellent agreement with the observations of fluxes taken by research aircraft during summer Monex 1979. It was found that broadband model output compared well with the absolute error less than $2 \%$. Hence, shortwave radiative heating profiles and shortwave surface fluxes were used in this study from the atlas by Ackerman and Cox (1986).

\subsection{Cloud top distribution}

Correct information of the horizontal and vertical distribution of clouds are required for the determination of radiation energy budgets. Cloud top pressure distribution for each $1^{\circ}$ by $1^{\circ}$ grid were computed using a technique analogous to that formulated by Cox and Griffith (1979). This method is basically a threshold method employing infrared satellite observations in the window region of the atmosphere. The details of the technique has been illustrated by Cox and Griffith (1979); Ackerman et al (1980); Minnis and Harrison (1984); and Rossow et al (1985). Cloud top pressure distribution was computed using data collected by the Visible-Infrared Spin Scan Radiometer (VISSR) onboard the geostationary GOES (IO) satellite. This satellite was positioned at about $60^{\circ} \mathrm{E}$ over the Indian region as mentioned earlier. The visible and infrared measurements in the spectral bands .5-.85 micron and 10-12.5 micron were used in the cloud top retrieval. Eight observations per day $(2,5,8,11,14,17,20$ and 23 UTC) were considered for estimates of diurnal fluctuations. During summer monsoon 1979 there were some problems with sensors onboard the GOES-(IO) satellite and therefore consistent day to day evolution of the southwest summer monsoon was not possible. Thus, the cloud distribution was averaged over the periods representing the post-onset phase of monsoon i.e., (23rd-30th June). Five-degree mean cloud top distribution in $\%$ as a 

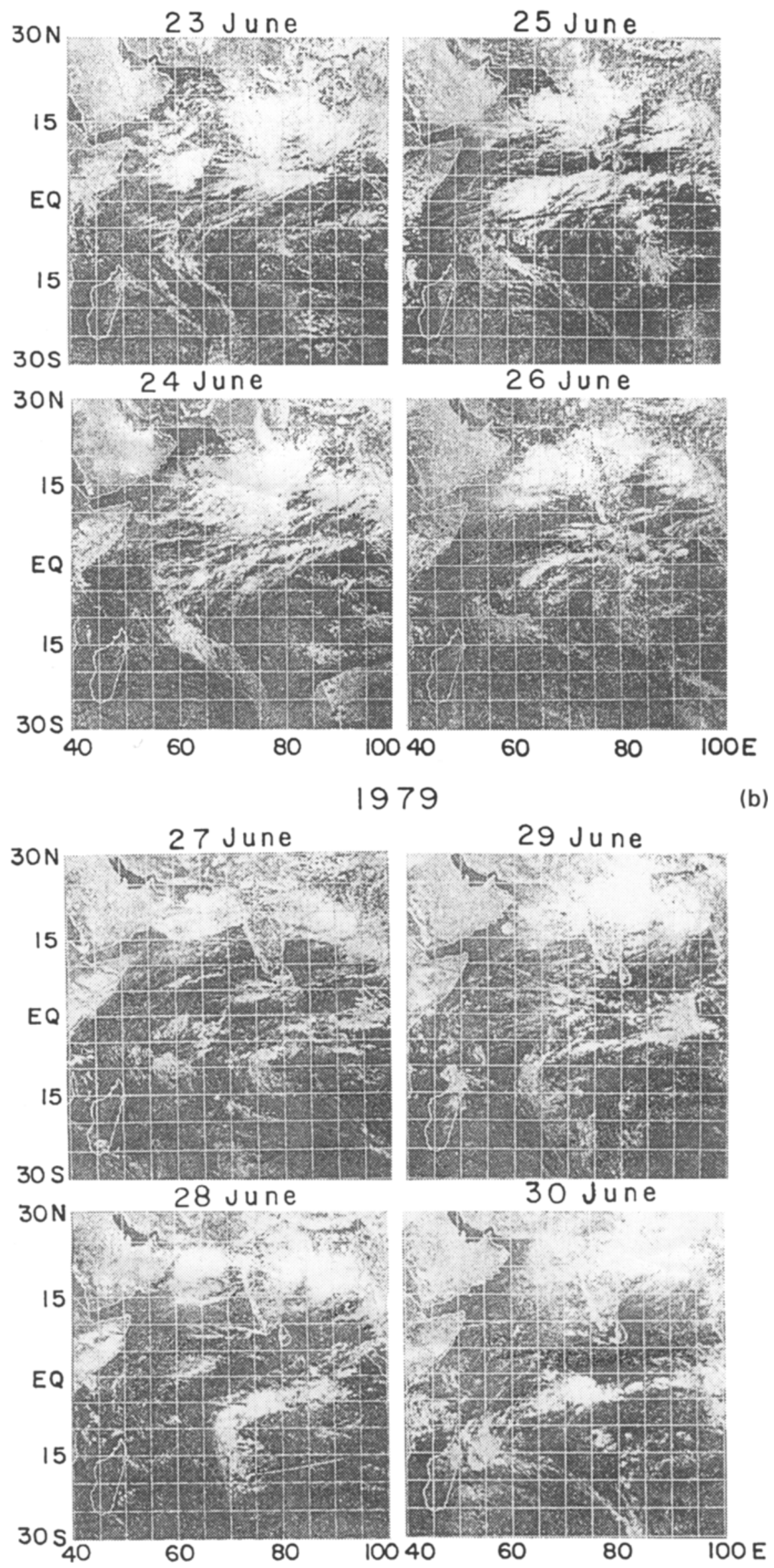

29 June

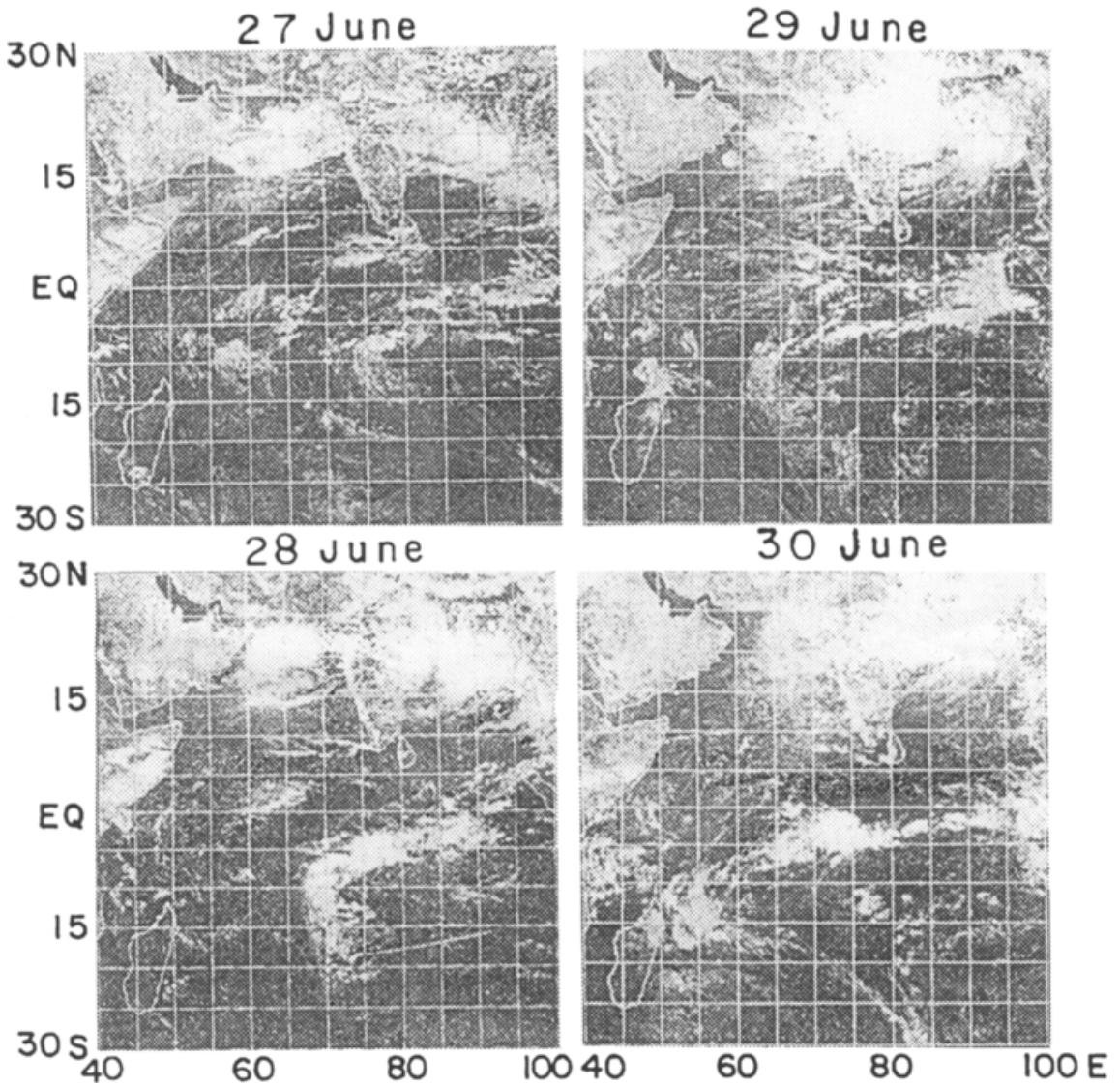

b)

Figure 1( $a$ and $b)$. TIROS-N visible cloud imagery during the post-onset period of summer monsoon. 

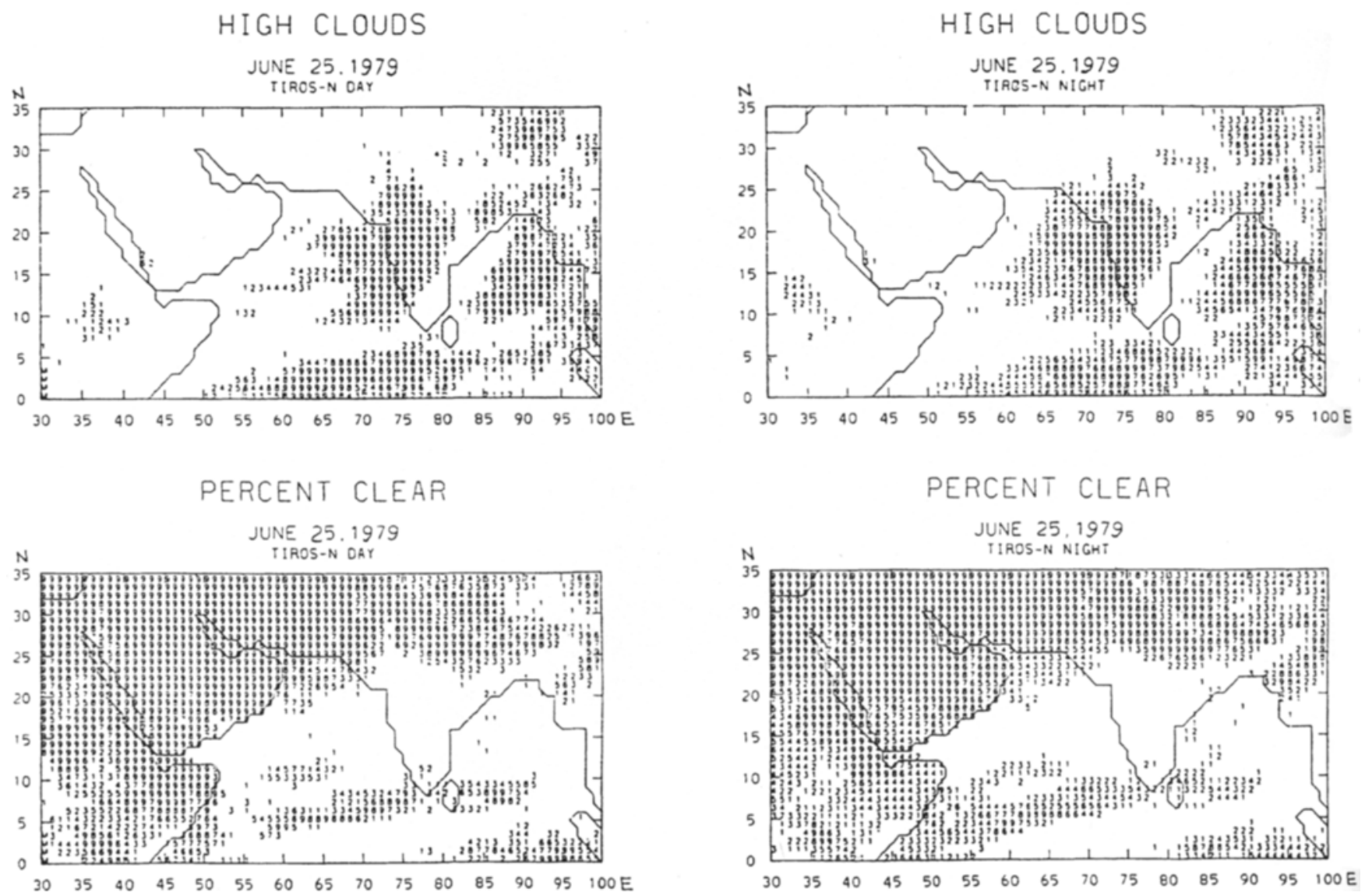

Figure 2. High clouds and per cent clear for day and night passes of TIROS-N on 25th June 1979 associated with the formation of the depression over the Bay of Bengal.

function of pressure (Ackerman and Cox 1986) were considered in this study.

\subsection{Satellite observed cloud imagery}

Day to day variations in cloud cover for the summer monsoon of 1979 were derived from mapped digital data from the TIROS-N multichannel Advanced Very High Resolution Radiometer (AVHRR). TIROS-N was sun-synchronous polar orbiting satellite with equatorial crossing times of 0300 (descending node) and 1500 (ascending node) mean solar time. Global Area Coverage (GAC) data which were available from NESDIS from channel 1 (.552-.904 micron) in visible range and channel 4 (10.52-11.45 micron) in infrared range were used for the cloud retrieval. These satellite observed cloud imagery obtained from the atlas 'Summer monsoon windsets from geostationary satellite data' by Young et al 1980 were used for comparison with the radiative energy budget parameters.

\section{Methodology}

Since differential heating between land and ocean plays a dominant role in the southwest monsoon, it is important that the horizontal scale of radiative energy budget should be small enough to show these differences. Therefore, for the present study a spatial scale of $1^{\circ}$ latitude by $1^{\circ}$ longitude grid was selected to classify surface type (ocean and land). The determination of radiation energy budget (REB) for each $1^{\circ}$ by $1^{\circ}$ grid requires a tremendous amount of computer time and hence REB was computed on a layer spatial scale. The area of interest extending from $30^{\circ} \mathrm{N}-30^{\circ} \mathrm{S}$ and $40^{\circ} \mathrm{E}$ to $100^{\circ} \mathrm{E}$ was divided into $1^{\circ}$ by $1^{\circ}$ sub divisions. Each $1^{\circ}$ by $1^{\circ}$ division was classified as land and ocean. Radiative calculations were made for each subregion for each $5^{\circ}$ by $5^{\circ}$ grid. Radiative heating profiles and surface fluxes were derived for day time and night time periods at a spatial resolution of $1^{\circ}$ for different phases of summer monsoon. The resulting fields were then averaged to produce 24 hour mean profile with a spatial resolution of $5^{\circ}$. Similarly, isopleth analysis was made for shortwave and longwave radiative heating (1000 to $100 \mathrm{hPa}$ ) at different layers with the thickness interval of $100 \mathrm{hPa}$. This was produced to see the dominant role of shortwave/ longwave radiative heating during post-onset phase of summer monsoon. Net 24 hour profiles were generated by summing up the shortwave and longwave radiative heating profiles. Then, isopleth analysis of all these 
radiative energy budget parameters was performed for the post-onset period of summer monsoon.

These analysed fields for surface and at different thickness pressure levels were compared with conventional fields reported by Dopplick (1974) over the Indian region. The radiative energy balance is considered mainly north of $10^{\circ} \mathrm{S}$ since the major convective activity during the monsoon is generally confined over this region for the above phase of monsoon.

\section{Radiative energy budget}

\subsection{Cloud imagery}

During the post-onset period (23rd-30th June 1979) three distinct weather systems were observed over the Indian Ocean i.e., two depressions over the Bay of Bengal and SHET (Southern Hemispheric Equatorial Trough) over the south Indian Ocean. Most of the cloudiness pattern was confined to these systems. Major convective cloud cluster was observed over northwest Bay of Bengal in association with the formation of the depressions on 23rd June 1979 and its landfall on 24th June 1979. Another depression which was formed over the head Bay on 28th June 1979 dominated large scale convective activity over north Bay and the surrounding land area. During 27th-30th June 1979, SHET was active and more convective activity was observed over this region between the equator and about 10 degree south. During the same period one distinct cloud cluster was observed over the north Arabian Sea. Day to day variations in cloudiness patterns as observed through TIROS-N satellite are depicted in figure $1(\mathrm{a}, \mathrm{b})$ for the post-onset period of summer monsoon 1979. For monitoring high cloud cover and cloud free cover (in per cent) for the day and night passes of the TIROS-N, the pressure distribution criteria was adopted. The cloud tops whose pressure was less than $400 \mathrm{hPa}$ were considered convectively active. The legend for cloud top pressure distribution is as follows: less than $10 \%=$ blank, $10-19 \%=1$, $20-29 \%=2, \quad 30-39 \%=3, \quad 40-49 \%=4,50-59 \%=5$, $60-69 \%=6,70-79 \%=7,80-89 \%=8,90-100 \%=9$, missing data $=M$. Figure 2 depicts high clouds and per cent clear for day and night passes of TIROS-N satellite associated with the depression lying over Orissa on 25th June 1979. Another huge cloud cluster extending from $57^{\circ} \mathrm{E}$ to $85^{\circ} \mathrm{E}$ was noticed over the equatorial region.

\subsection{Surface fluxes and cloud top distribution}

Shortwave surface fluxes were very less $\left(160 \mathrm{~W} / \mathrm{m}^{2}\right)$ over the central part of India associated with convective cloudiness of the monsoon depression. However, the values did not become the lowest

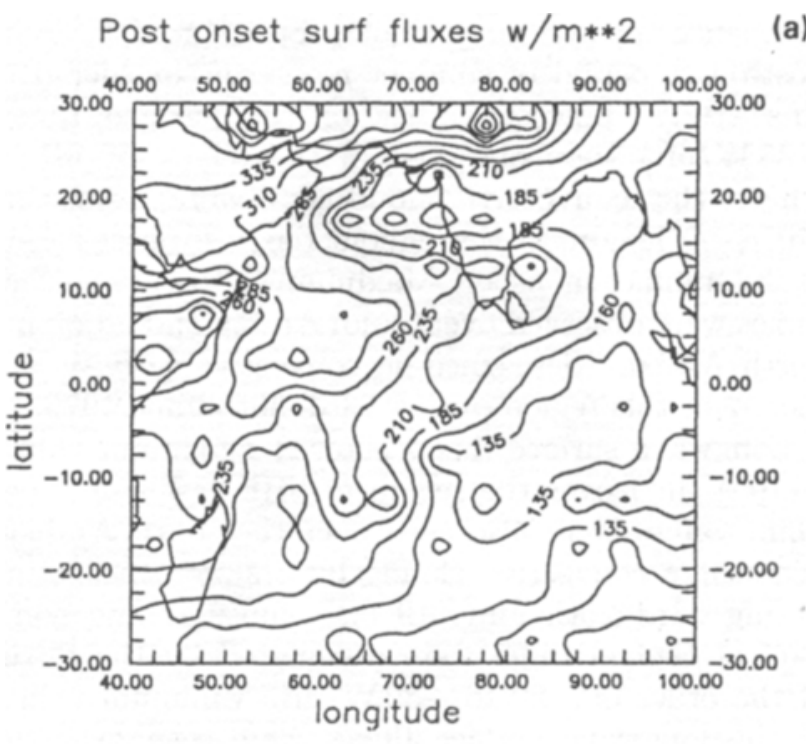

(a)

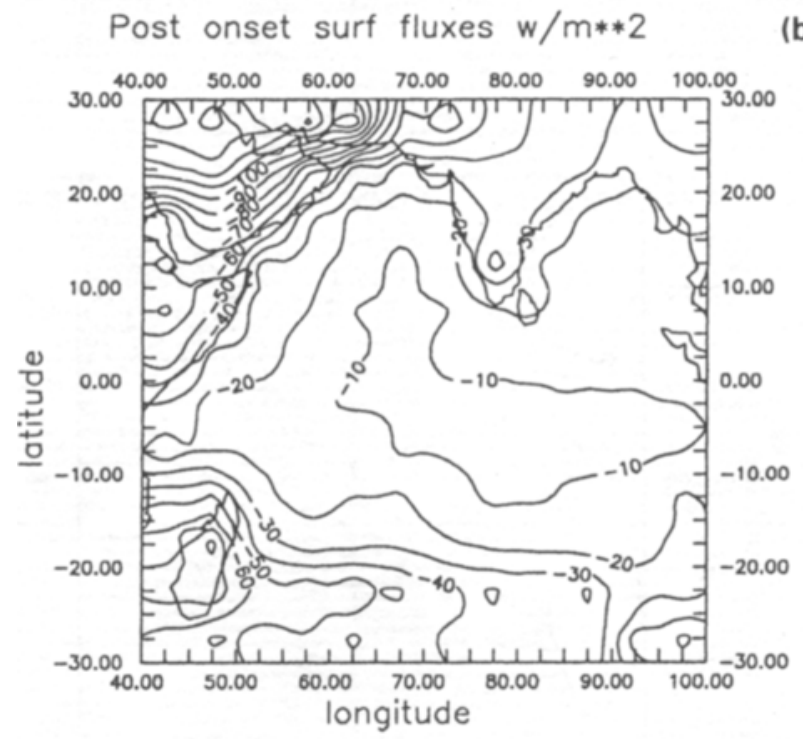

(b)

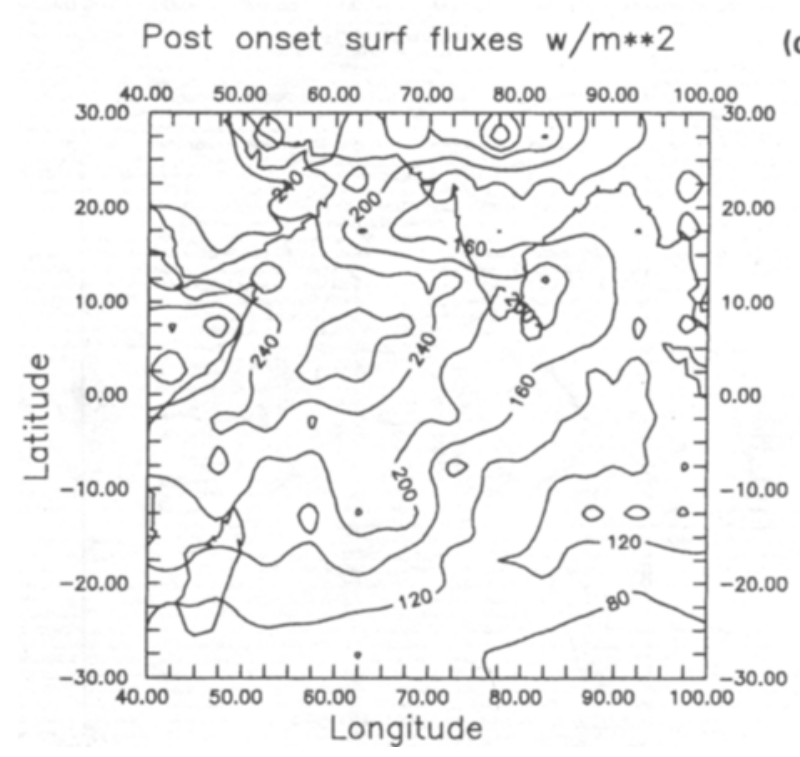

Figure 3(a,b and $c)$. Mean shortwave, longwave and net surface fluxes during the post-onset period. 
one, since the system did not persist throughout the post-onset period of summer monsoon considered in this study. Lowest values of the surface fluxes $\left(135 \mathrm{~W} / \mathrm{m}^{2}\right)$ were observed in the region of SHET where the convective cloudiness were persisting $\left(70^{\circ} \mathrm{E}-90^{\circ} \mathrm{E}\right)$ almost throughout the post-onset period of the summer monsoon. Maximum shortwave surface fluxes were observed over Saudi Arabia and adjoining north Arabian Sea, since no convective activity was seen over this region during 23rd-30th June 1979.

Longwave surface fluxes showed maximum values $\left(-10 \mathrm{~W} / \mathrm{m}^{2}\right)$ over the region of SHET. These maximum values were also seen over the south Arabian Sea where convective cloud clusters were persisting during 23rd-25th June 1979. Peninsular and some part of central India were dominated by the fluxes of the order of -20 to $-30 \mathrm{~W} / \mathrm{m}^{2}$. Minimum values of the longwave surface fluxes were seen over the region of Saudi Arabia. Lowest net surface fluxes
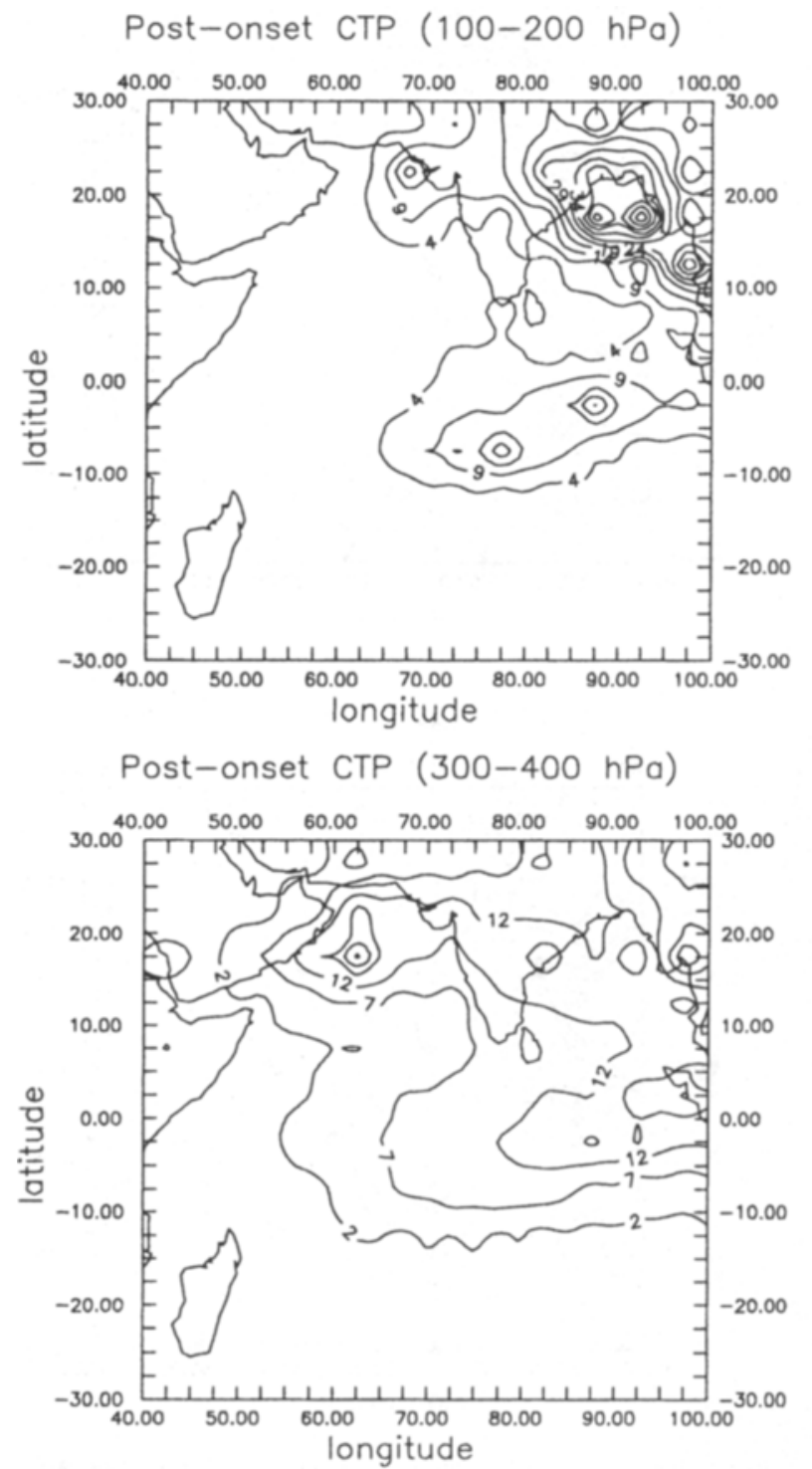

$\left(120 \mathrm{~W} / \mathrm{m}^{2}\right)$ were noticed in the region of SHET. Central India showed lower values of net fluxes $\left(160 \mathrm{~W} / \mathrm{m}^{2}\right)$. Saudi Arabia again showed maximum net fluxes of the order of $240 \mathrm{~W} / \mathrm{m}^{2}$ (figure 3 ).

Maximum values of cloud top distribution were found over the region of SHET, north Arabian Sea and the central Bay of Bengal, where the cloudiness patterns were dominating associated with different monsoon systems. These maximum values were confined to higher levels of the troposphere i.e., 100$200 \mathrm{hPa}$ layer. The values of the cloud top distribution were seen generally decreasing from higher levels to lower levels throughout the troposphere (figure 4).

\subsection{Shortwave Radiative Heating (SRH)}

Shortwave radiative heating was found to be maximum $\left(1.96^{\circ} \mathrm{C} /\right.$ day $)$ over the central and adjoining northeast Bay for $100-200 \mathrm{hPa}$ layer, where cloud
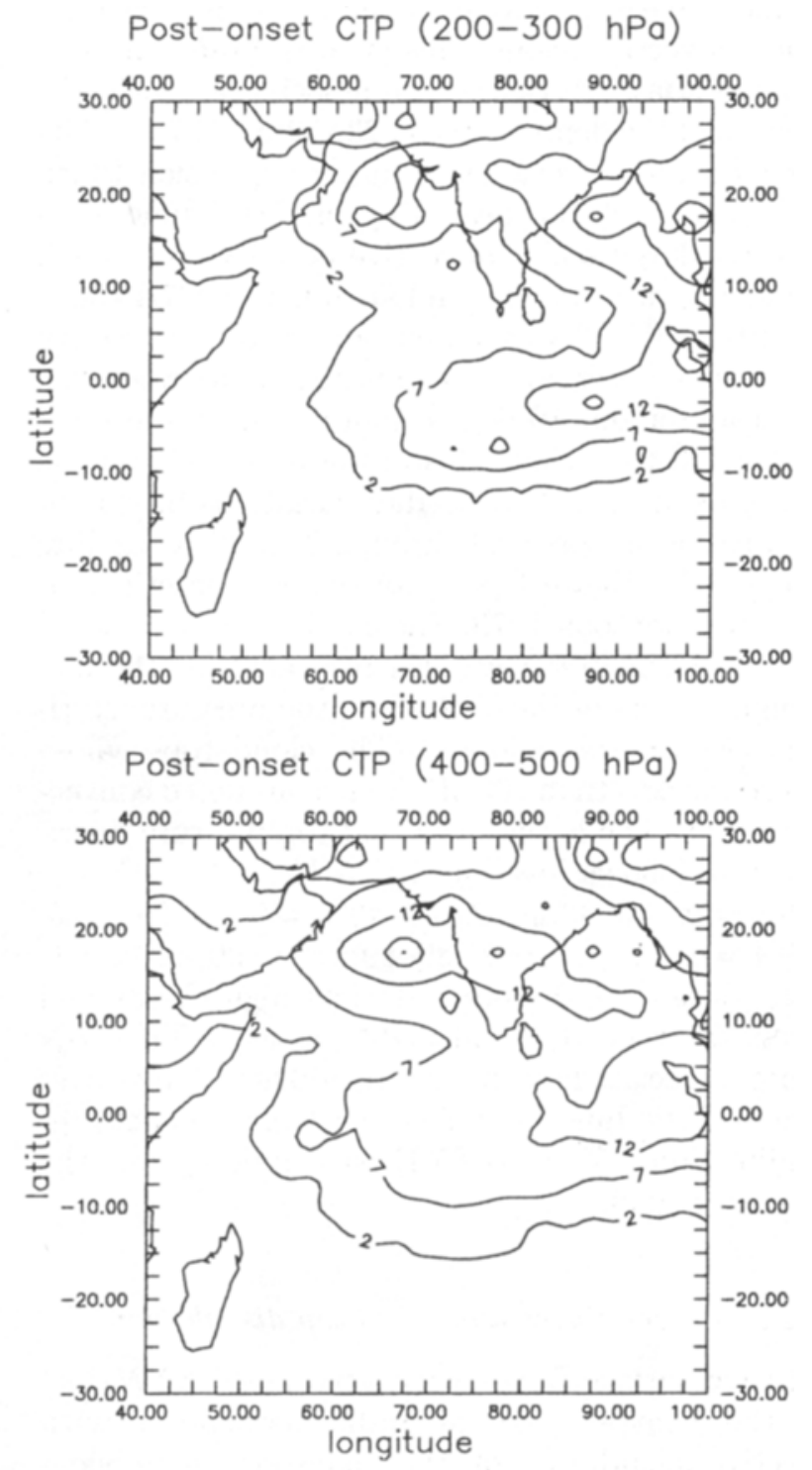

Figure 4. (Continued) 

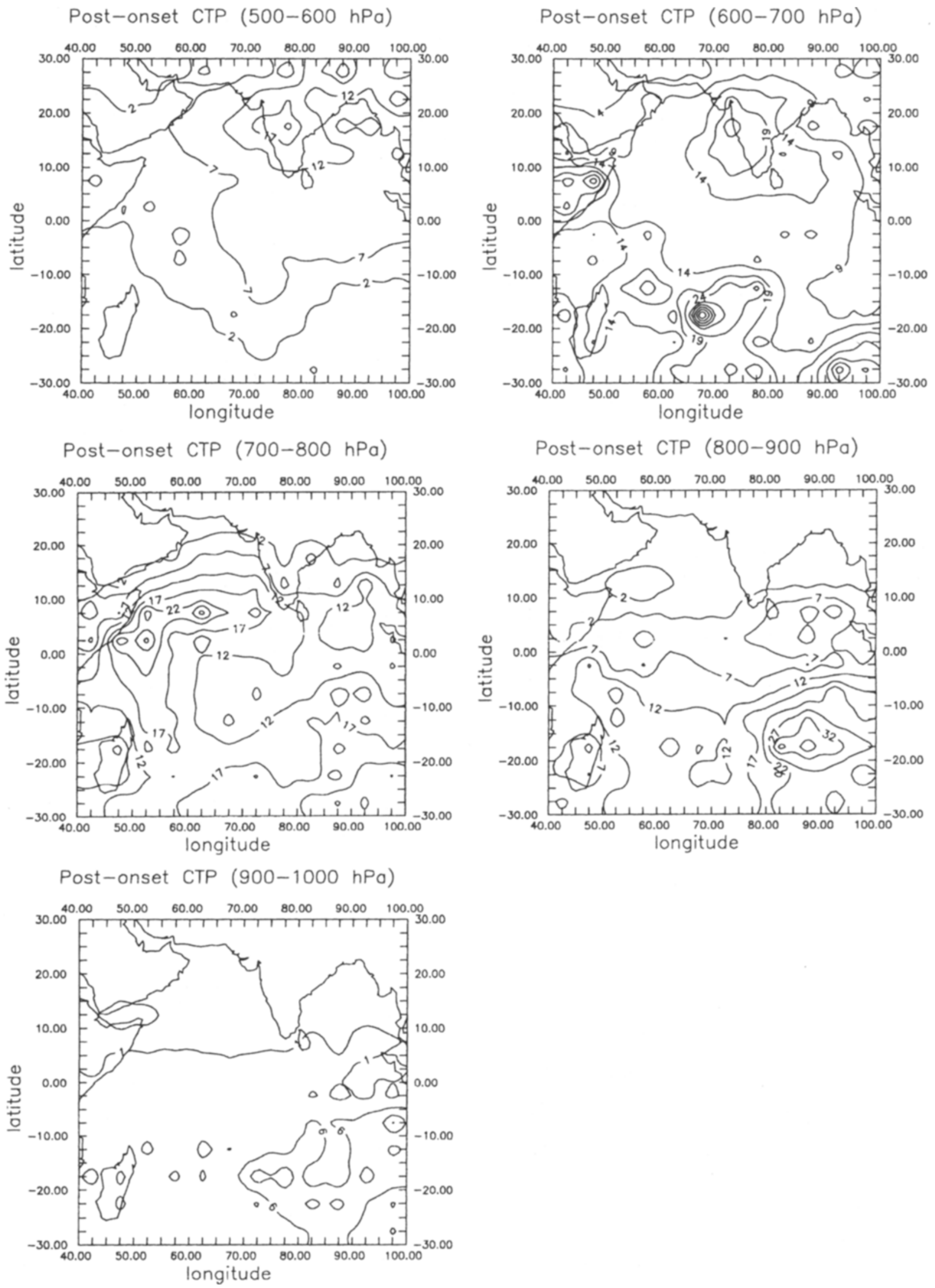

Figure 4. Mean cloud top pressure distribution during the post-onset period. 
clusters associated with monsoon depressions were prevailing for most of the post-onset period. Higher values $\left(0.9^{\circ} \mathrm{C} /\right.$ day $)$ were noticed over northeast Arabian Sea and the surrounding Gujarat area. This was associated with the convective activity, particularly during 25th-30th June 1979. Similarly, higher values of SRH $\left(0.6^{\circ} \mathrm{C} /\right.$ day $)$ were seen over the region of SHET associated with convective activity during 28th-30th June 1979. The shortwave radiative heating was seen decreasing at lower tropospheric layers except for $500-700 \mathrm{hPa}$ layer. In this layer SRH values were comparatively more (figure 5).

\subsection{Longwave Radiative Heating (LRH)}

Longwave radiative cooling was observed over the region of major convective activity, particularly over northeast Arabian Sea $\left(-0.64^{\circ} \mathrm{C} /\right.$ day $)$, central Bay of Bengal $\left(-1.77^{\circ} \mathrm{C} /\right.$ day) and over the SHET area $\left(-0.48^{\circ} \mathrm{C} /\right.$ day $)$ for $100-200 \mathrm{hPa}$ layer. Longwave radiative heating of the order of 0.05 to $0.14^{\circ} \mathrm{C} /$ day was found to persist for this layer in the remaining domain of the study. As compared to $100-200 \mathrm{hPa}$ layer more longwave radiative cooling was seen to persist for this layer in the remaining domain of the study (figure 6).

\subsection{Net Radiative Heating (NRH)}

Net radiative heating was found to be positive at the upper tropospheric layer i.e., $100-200 \mathrm{hPa}$ for the whole domain of the study. Maximum of NRH $\left(1.2^{\circ} \mathrm{C} /\right.$ day and $0.9^{\circ} \mathrm{C} /$ day $)$ were seen in the two pockets around $10^{\circ} \mathrm{S}, 80^{\circ} \mathrm{E}$ and $5^{\circ} \mathrm{S}, 88^{\circ} \mathrm{E}$ respectively. These were associated with persistent convective
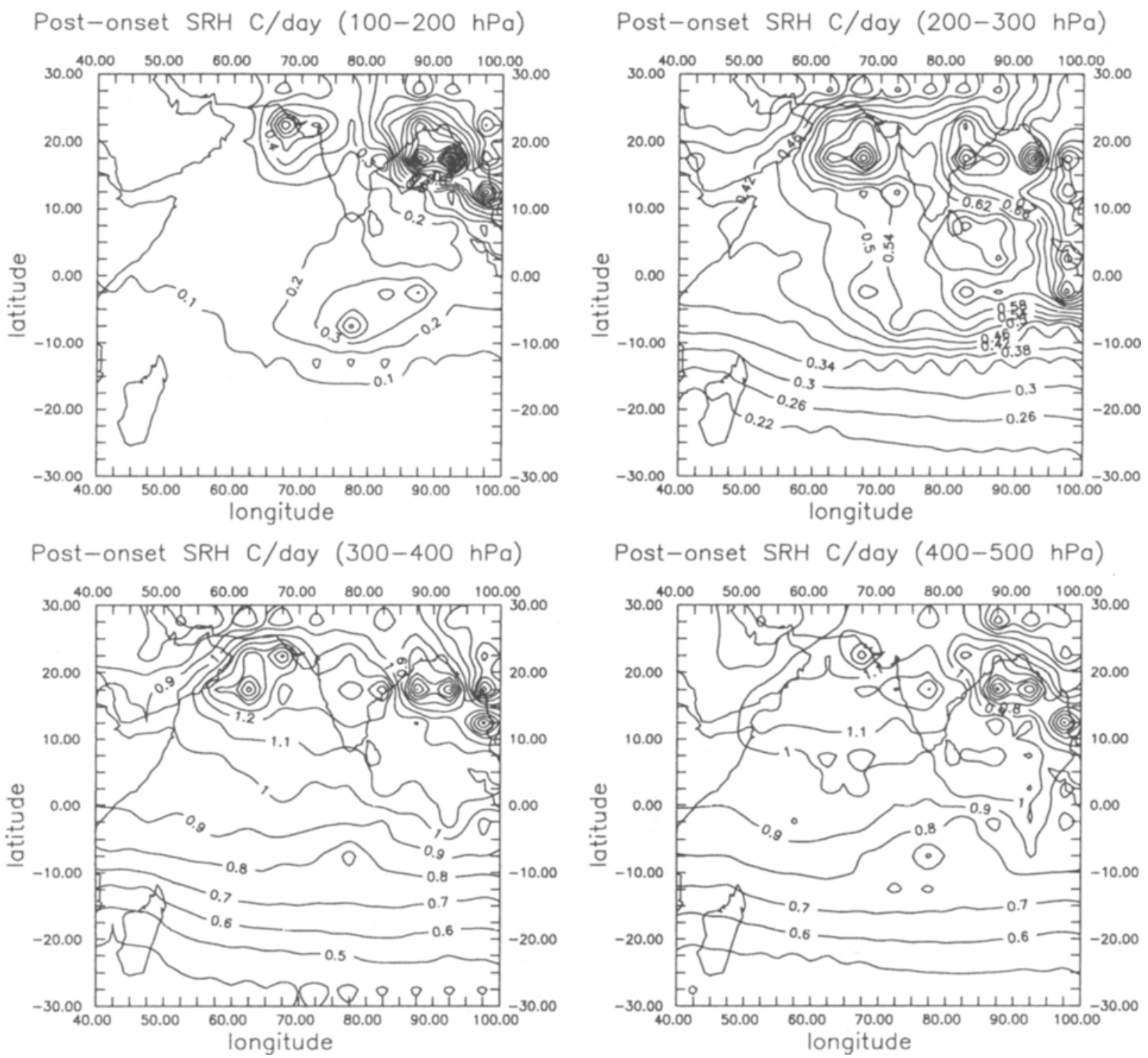

Figure 5. (Continued) 

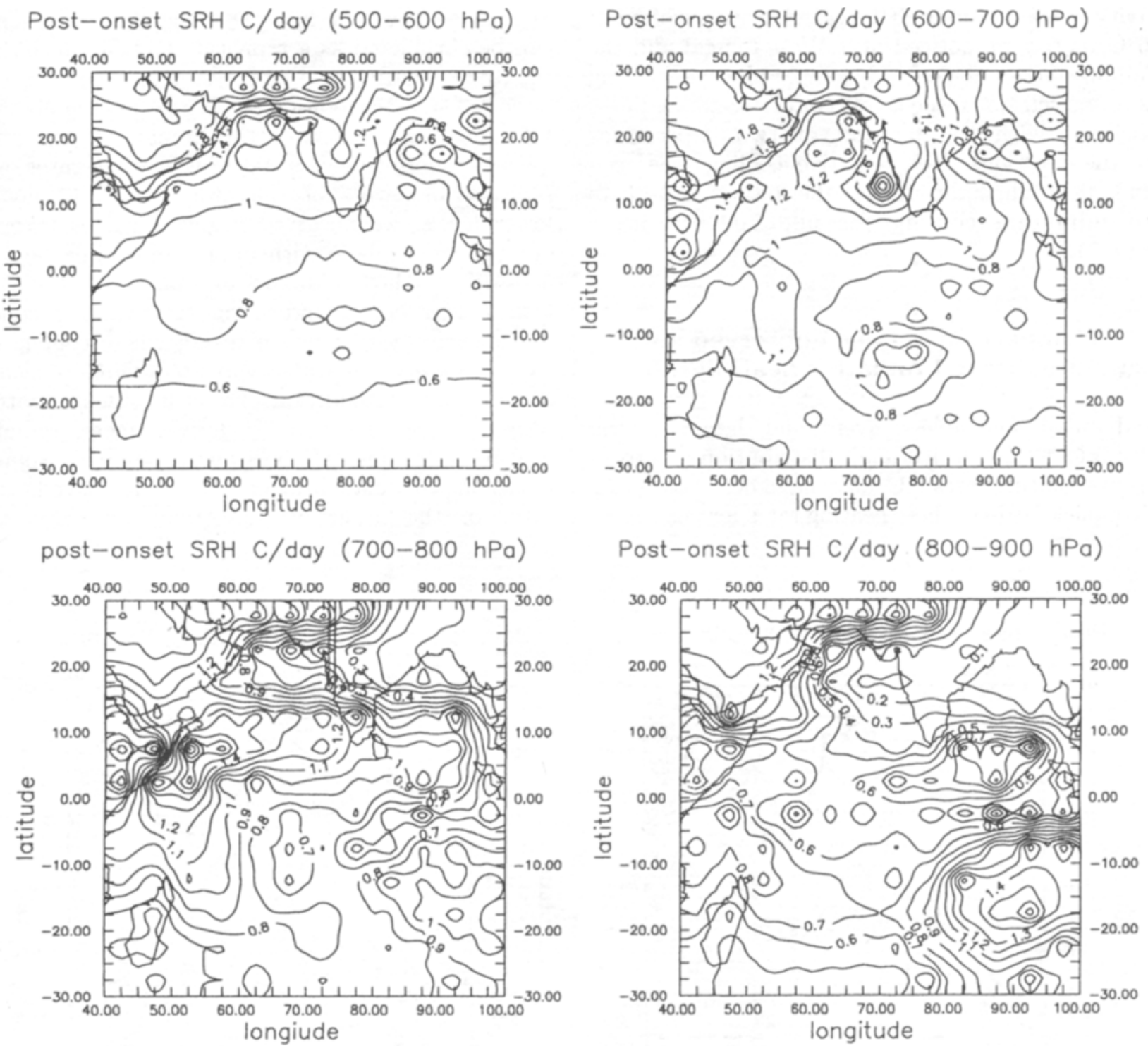

Post-onset SRH C/day (900-1000 hPa)

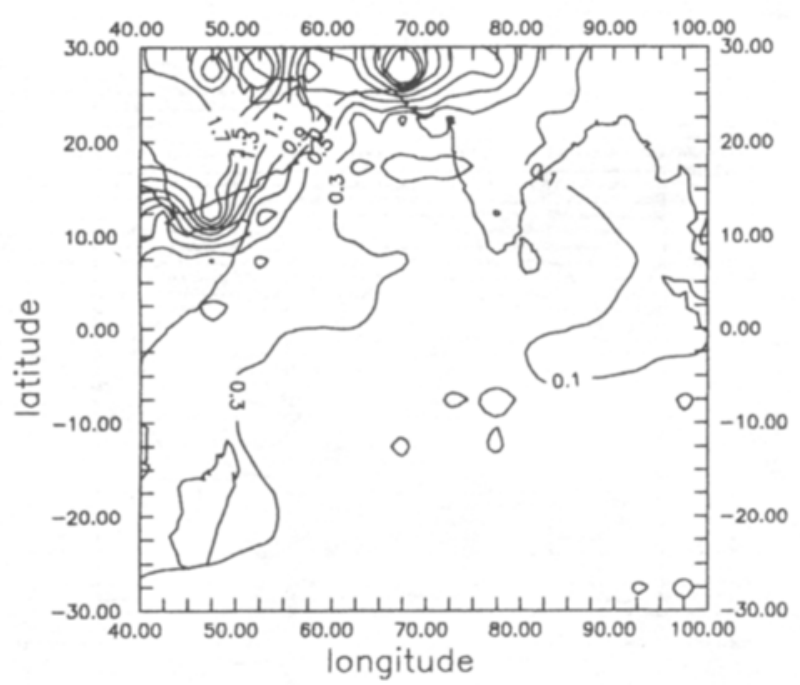

Figure 5. Mean shortwave radiative heating during the post-onset period. 
activity in the region of SHET. Higher values of NRH $\left(0.6^{\circ} \mathrm{C} /\right.$ day $)$ were noticed over West Bengal and the adjoining Orissa region. This net radiative heating was observed in respect of convective cloudiness associated with the landfall of two depressions over these regions. Net radiative cooling was seen from 200-100 hpa throughout the lower troposphere with minimum cooling for $500-700 \mathrm{hPa}$ layer (figure 7).

\section{Comparison between observed and satellite-derived radiative heating rates}

Based on all available conventional data over the entire globe the latitudinal distribution of total radiative heating rates $\left({ }^{\circ} \mathrm{C} /\right.$ day $)$ have been computed by Dopplick (1974). These heating rates for post-onset month is shown in figure 8. Therefore, this figure can be considered as a representative figure showing the total radiative heating rates during the post-onset period of summer monsoon. After examining observed total heating rates over the domain of the study it was found that at $100 \mathrm{hPa}$ heating rates were positive and were of the order of $0.2^{\circ} \mathrm{C} /$ day. In lower levels, we observed negative values throughout the troposphere with minimum cooling between $500-700 \mathrm{hPa}$ layer. Maximum values of total radiative cooling were found in the tropical troposphere, particularly over monsoon region where cooling due to the presence of water vapour dominates heating due to solar absorption. Exactly, similar features were observed for satellite-derived mean radiative heating rates for the post-onset phase of summer monsoon 1979. Satellite-derived net radiative heating rates of the order of $0.2^{\circ} \mathrm{C} /$ day were generally
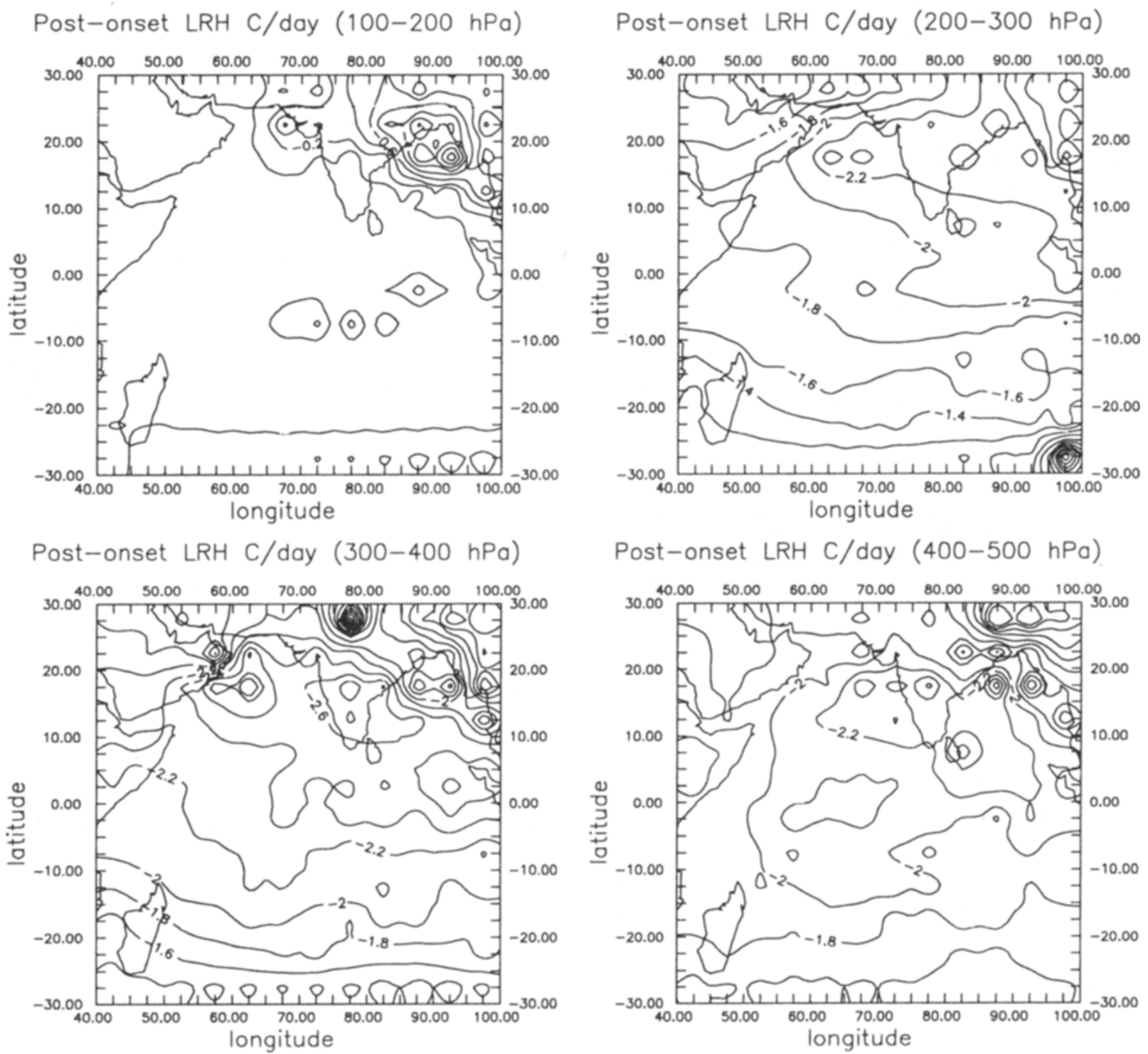

Figure 6. (Continued) 

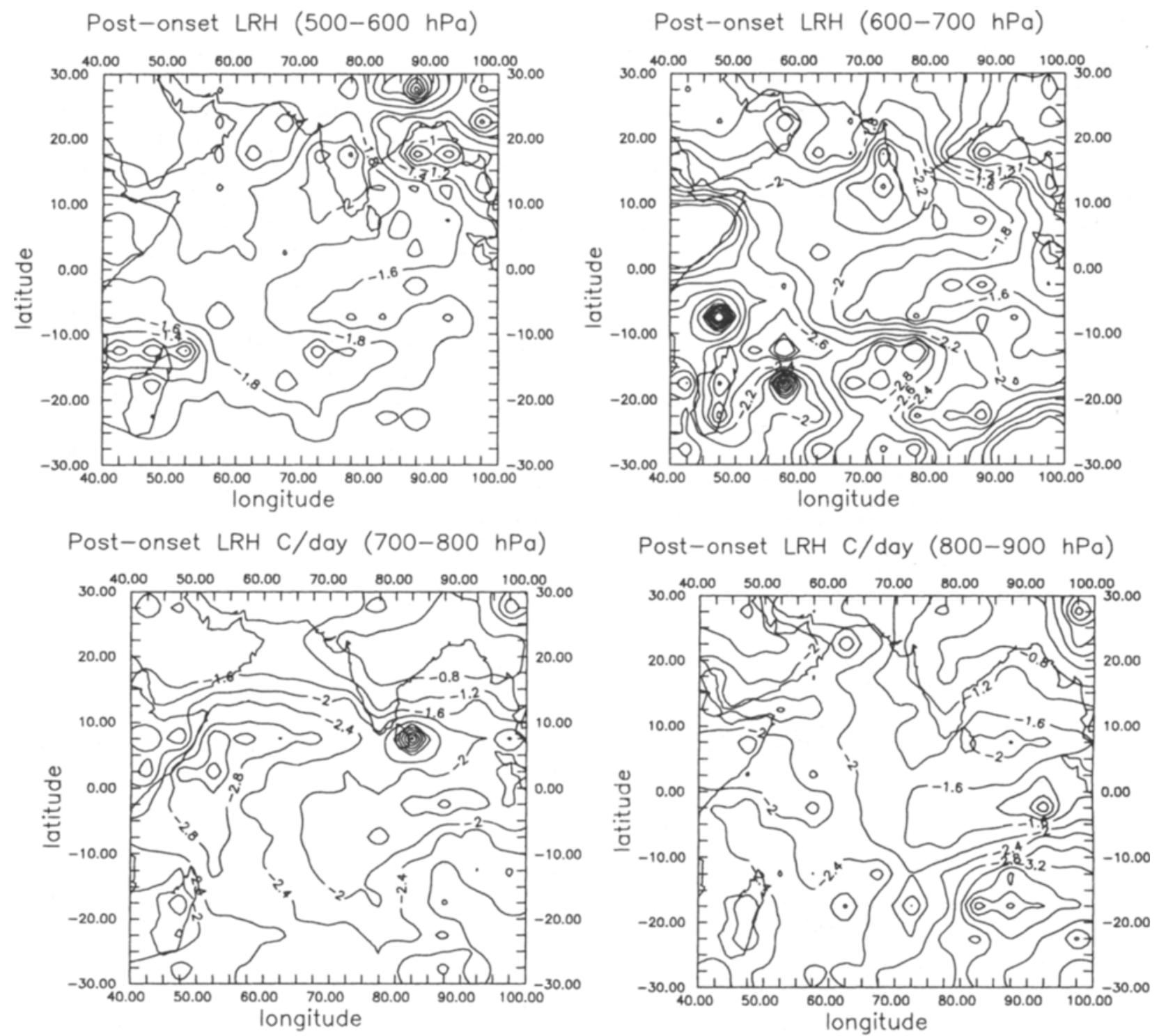

Post-onset LRH C/day (900-1000 hPa)

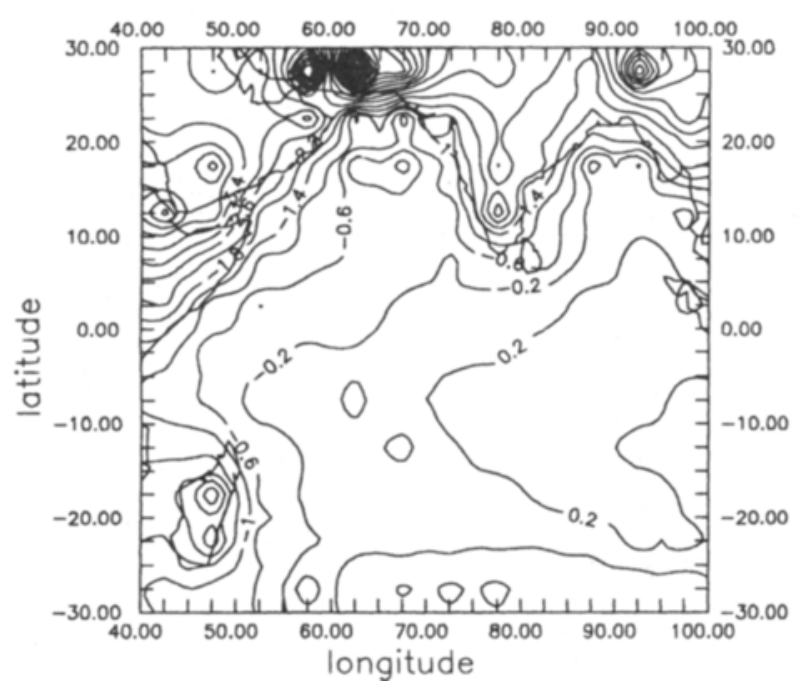

Figure 6. Mean longwave radiative heating during the post-onset period. 
observed for $100-200 \mathrm{hPa}$ layer except some major consistent convective activity regions, where values were comparatively higher. In this case also minimum cooling was observed for $500-700 \mathrm{hPa}$ layer. This effect was encountered because the latent heat released was maximum for this layer. Results of our study indicate that satellite derived radiative energy budget data are well comparable with the observed data over the domain of the study.

\section{Conclusion}

In this study, satellite-derived radiative energy balance (shortwave radiative heating, longwave radiative heating and net radiation balance) at different layers from surface to $100 \mathrm{hPa}$ have been thoroughly illustrated for the post-onset phase of summer monsoon 1979. Satellite-derived net radiative heating rates for each $100 \mathrm{hPa}$ layer from surface- $100 \mathrm{hPa}$ have been computed and compared with the observed latitudinal distribution of total radiative heating rates over the Indian region. It was found that on the average similar characteristic features such as radiative heating at the upper tropospheric level $(100-200 \mathrm{hPa})$, cooling throughout the lower layers (200-1000 hPa) and minimum cooling for $500-700 \mathrm{hPa}$ layer were observed for both satellite-derived and observational radiative energy budgets. In this study only data of one year have been used and the results are very much encouraging. However, one has to verify the radiative energy budget data for other years too. It may demonstrate promising results for the evolution of the complete life cycle of summer monsoon over the Indian region.
Post Net heating C/day $\quad(100-200 \mathrm{hPa})$

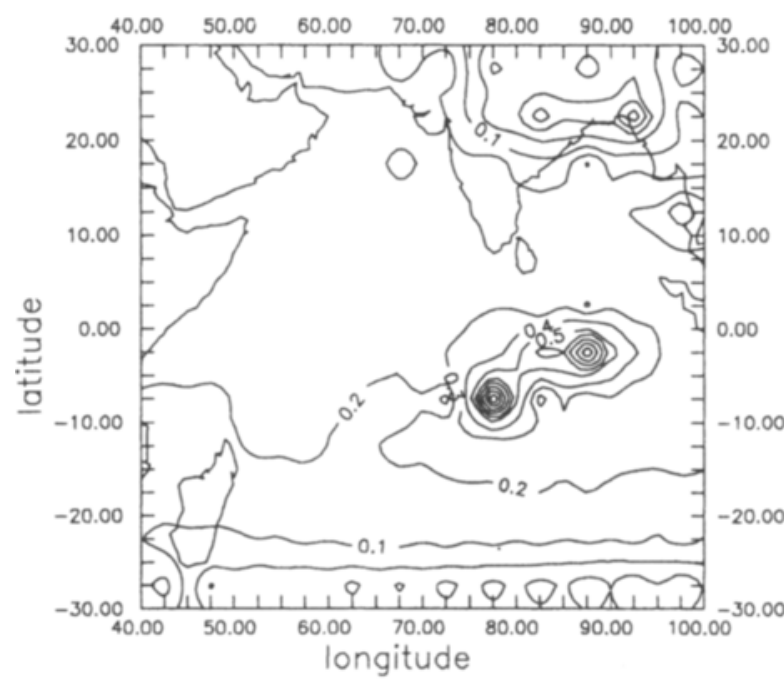

Post Net heating C/day (300-400 hPa)

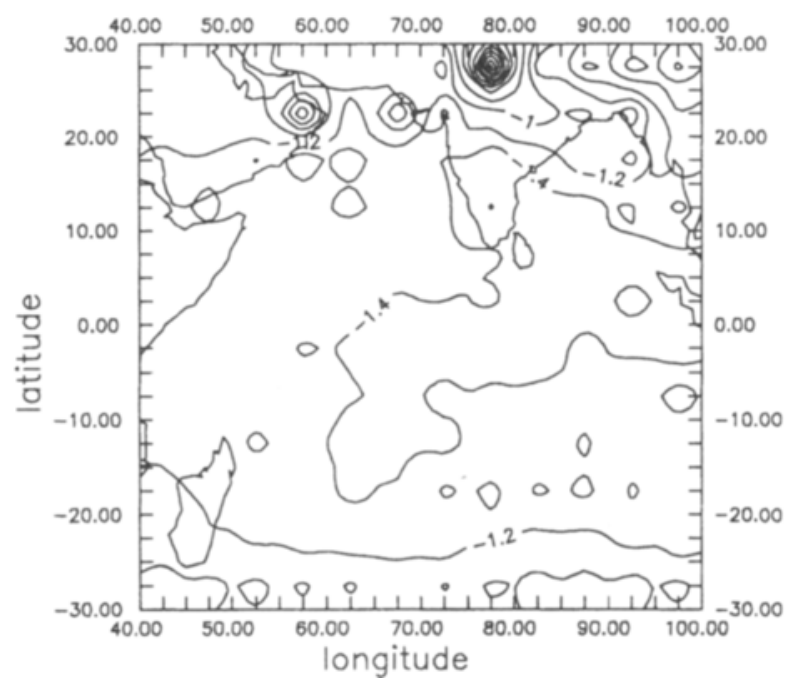

Post Net heating C/day (200-300 hPa)

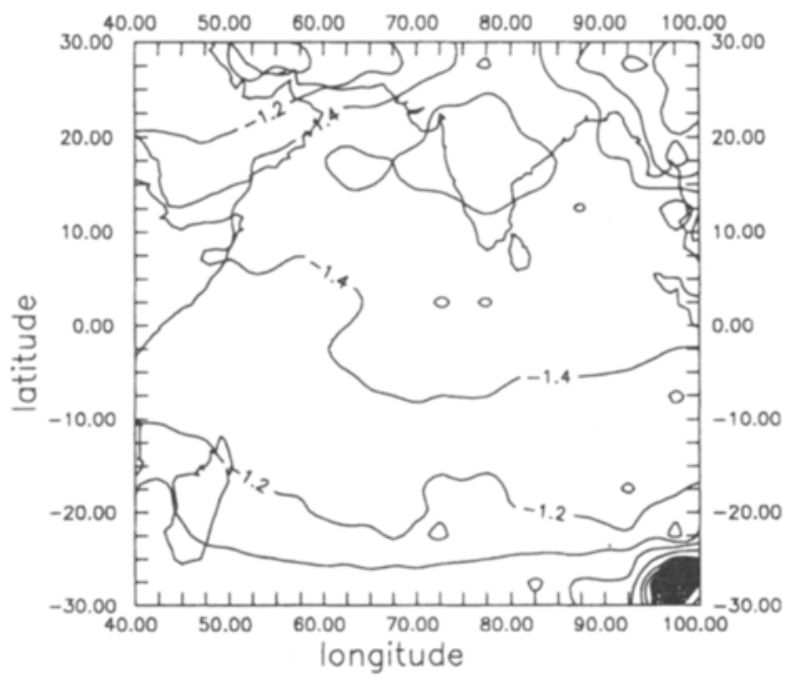

Post Net heating C/day (400-500 hPa)

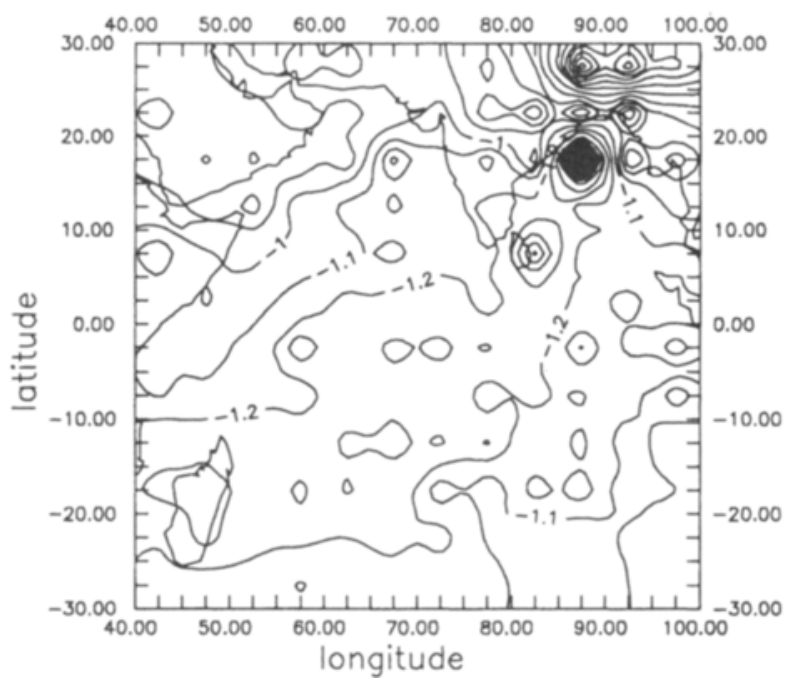

Figure 7. (Continued) 


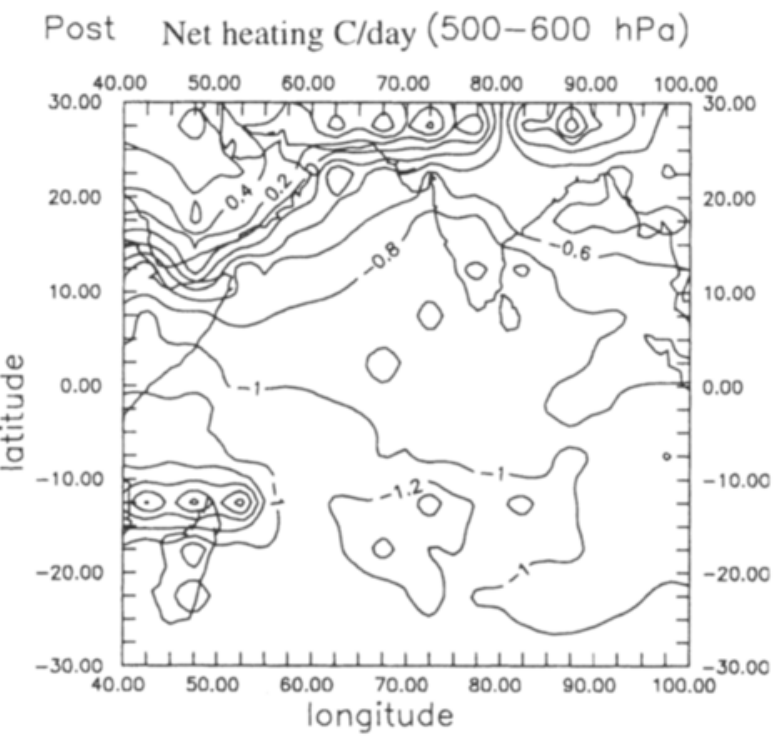

Post Net heating C/day $(700-800 \mathrm{hPa})$

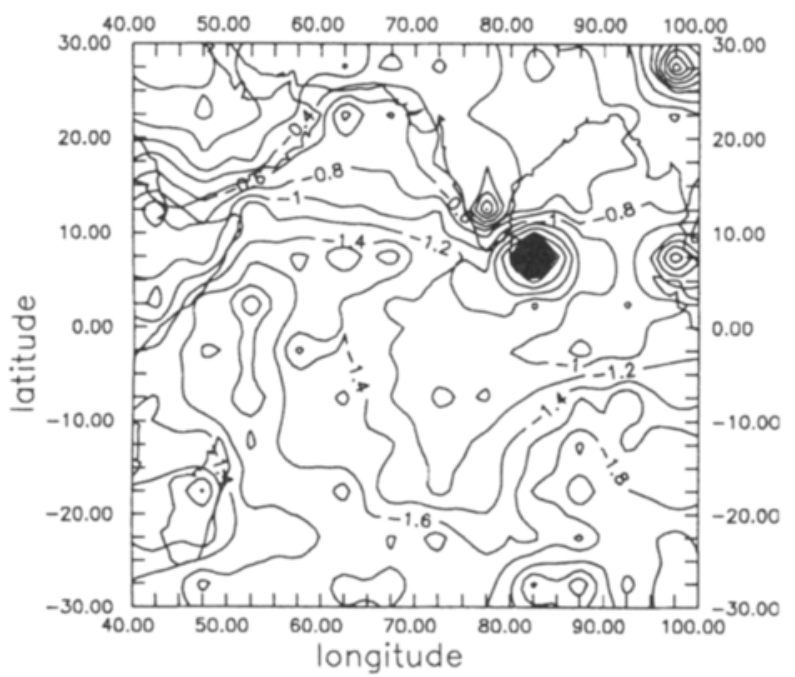

Post Net heating C/day (900-1000 hPa)

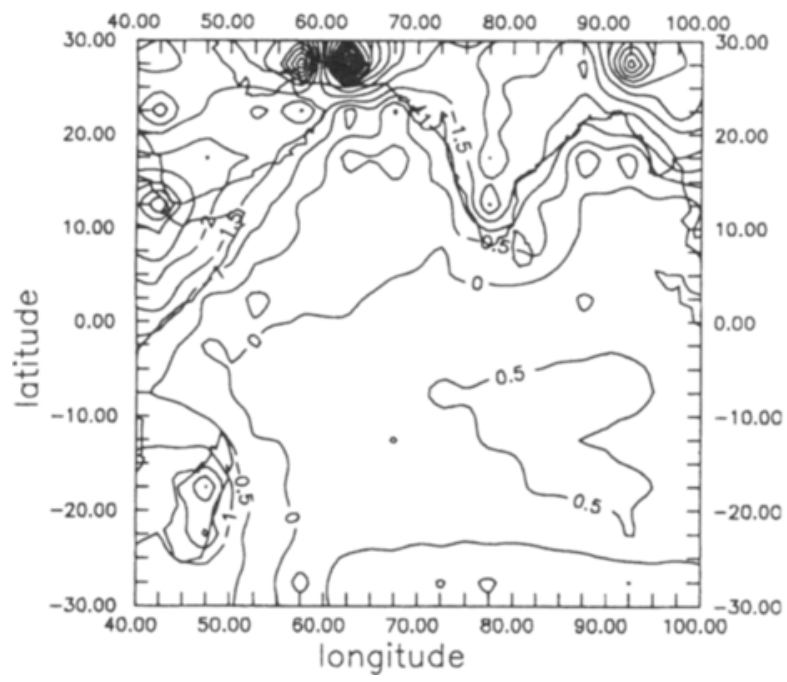

Post Net heating C/day $(600-700 \mathrm{hPa})$

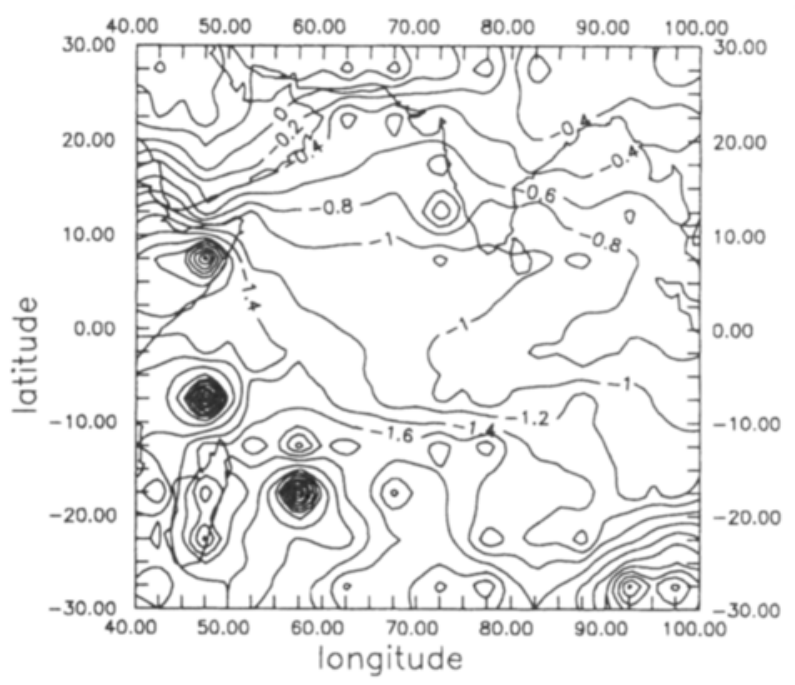

Post Net heating C/day $(800-900 \mathrm{hPa})$

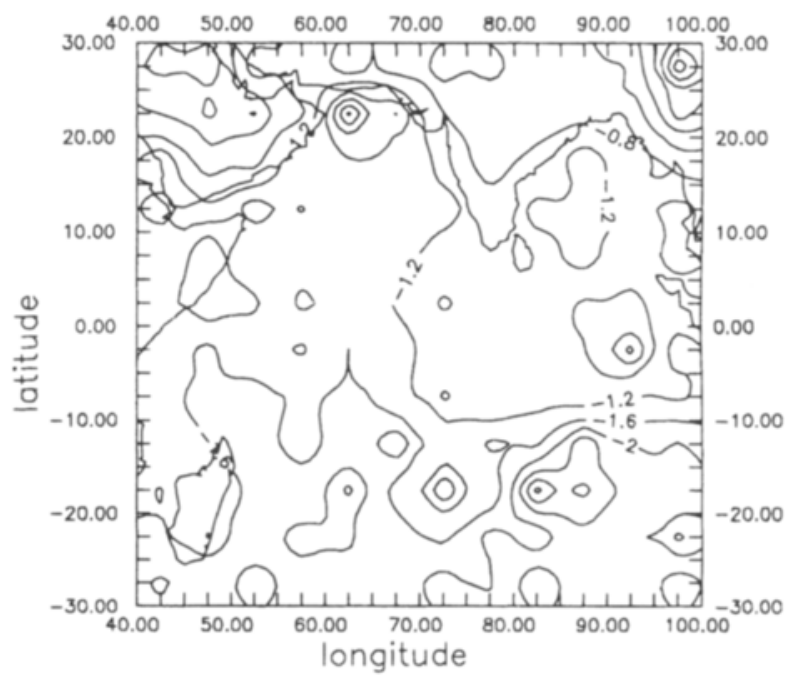

Figure 7. Mean net radiative heating during the post-onset period. 


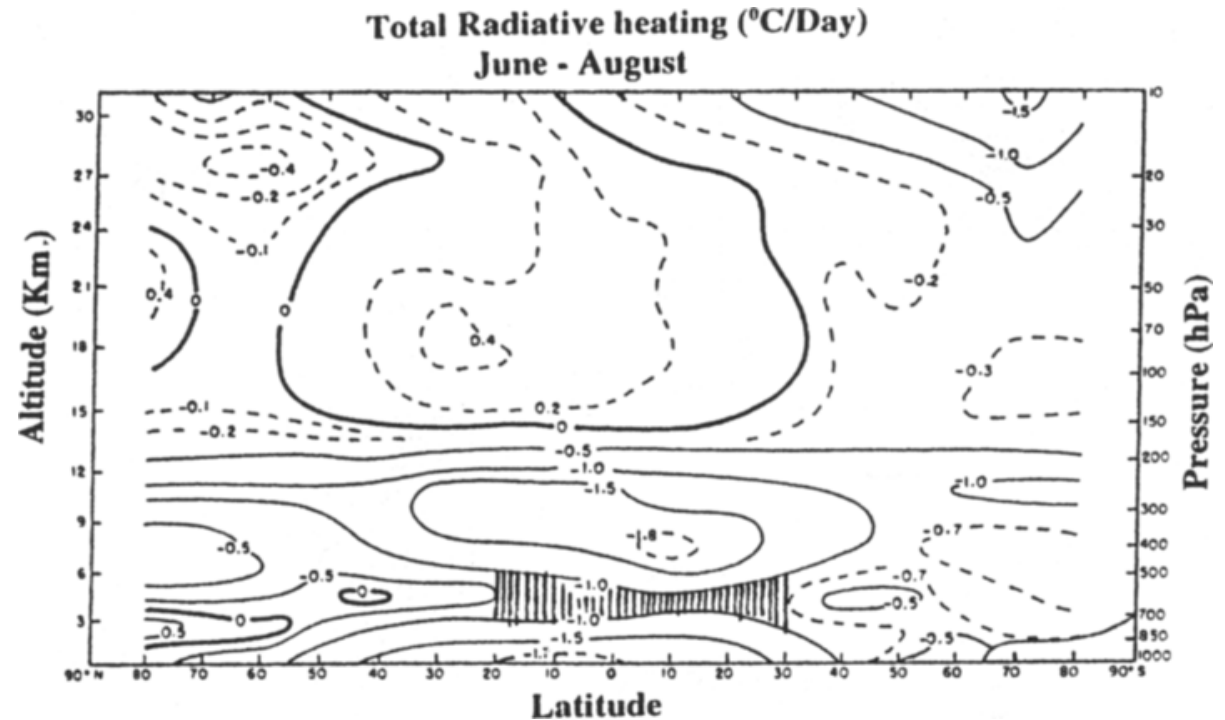

Figure 8. Observed mean net radiative heating during the monsoon months (after Dopplick 1974).

\section{Acknowledgements}

The authors wish to thank the Director, I.I.T.M. for providing facilities and showing keen interest in the study. Thanks are extended to Dr. S S Singh, Head, Forecasting Research Division for his encouragement and support during the period of study.

\section{References}

Ackerman S A, Steven A and Cox S K 1980 Colorado State University Radiation instrumentation and data reduction for the Convair 990 during summer Monex; Department of Atmospheric Science Report No. 325, Colorado State University, Fort Collins. Co. 72

Ackerman S A and Cox S K 1986 Radiative energy budget atlas of the 1979 Southwest summer monsoon, Department of Atmos. Sci., Colorado State University Fort Collins, Colorado $26-37$
Cox S K and Griffith K T 1979 Estimates of radiative divergence during phase III of the GARP Atlantic Tropical Experiment: Part I Meteorology; J. Atmos. Sci. 36 576-585

Dopplick T G 1974 Radiative heating in the atmosphere, The general circulation of the atmosphere and interaction with extratropical latitudes (eds) R E Newell, J W Kindson, D G Vincent and G J Boer (Cambridge, Massachusetts, London, England: The MIT Press)

Fien J S and Kuettner J P 1980 Report on summer Monex field phase; Bull. Amer. Meteorol. Soc. 61 461-474

Krishnamurty T N and Ramnathan Y 1982 Sensitivity of monsoon onset to differential heating; J. Atmos. Sci. 36 1290-1306

Minnis P and Harrison E F 1984 Diurnal variation of regional cloud and clear sky radiative parameters derived from GOES data. Part I: Analysis method; J. Appl. Meteor. 23 993-1011

Rossow W B, Mosher F, Kinsella E, Arkin A, Desbosis M, Harrison E, Minnis P, Rupercht E, Seze G, Simmer C and Smith E 1985 ISCCP cloud algorithm intercomparison; $J$. Appl. Meteorol. 24 877-903.

Young J A, Virji H, Wylie D P and Lo C 1980 Summer monsoon wind sets from geostationary satellite data (University of Wisconsin Madison USA) 1-27 